\title{
Temporal epileptic seizures and occupational exposure to solvents
}

\author{
Michael Jacobsen, Jesper Baelum, Jens Peter Bonde
}

\begin{abstract}
Long term exposure to organic solvents is usually not considered as a possible cause of chronic epileptic seizures. A case that shows a remarkable coincidence between exposure to organic solvents and occurrence of epileptic seizures is reported. The man was a 58 year old sign writer with lifelong exposure to a mixture of organic solvents (mainly cyclohexanone, white spirit, and isopropanol). Epileptic seizures of temporal type were occurring in relation to solvent exposure. The seizures disappeared shortly after stopping exposure but returned just after a short term re-exposure to cyclohexanone. The case history suggests that exposure to organic solvents may elicit or maintain epileptic seizures despite medical treatment.
\end{abstract}

(Occup Environ Med 1994;51:429-430)

Long term exposure to organic solvents is usually not considered a possible cause of chronic epileptic seizures. ${ }^{12}$ The case reported here shows a remarkable coincidence between exposure to a mixture of organic solvents and occurrence of epileptic seizures during a working period of 30 years.

\section{Case report}

The case was a 58 year old man. He had no familial dispositions to epilepsy, no disease prenatally, perinatally, or in childhood, and there was no history of trauma or abuse of alcohol.

From 14 to 24 years of age he was employed as a sign writer and from 24 until 52 as a silk screen printer. During this period he was heavily exposed to a mixture of several organic solvents including cyclohexanone, white spirit, and isopropanol. Cleaning of the printing frame was done manually, and both cleaning and printing procedures were performed without the use of local or general ventilation, or personal protective equipment. $\mathrm{He}$ often had symptoms of acute intoxication with headache, nausea, vertigo, a feeling of drunkenness, and intolerance to alcohol during the work.

From the age of 24 to 52 the printer had weekly to monthly seizures of uniform character. The seizures were preceded by a few days of irritability and were characterised by an aura lasting a few seconds, visual hallucina- tions, and depressed consciousness lasting a few minutes. Occasionally there was a total loss of consciousness, but the seizures were never accompanied by convulsions. Each seizure was followed by tiredness lasting several days. They were resistant to treatment by combinations of phenytoin, phenobarbitone, primidone, and carbamazepine. Throughout the years electroencephalograms (EEGs) showed low frequency activity mixed with occasional spikes over the temporal region with changing right and left side dominance.

When the printer became a specialist teacher at the age of 52-work without exposure to organic solvents-the epileptic seizures disappeared within 12 months. The medical treatment was withdrawn and coincidentally the EEG became normal.

Four years later he was re-exposed during three days to high levels of cyclohexanone, and two days after this he again had a single epileptic seizure similar to those earlier.

In the past years he has had no exposure to solvents and no epileptic seizures. He does not show symptoms compatible with chronic toxic encephalopathy, ${ }^{2}$ and cerebral computed tomography has been normal.

\section{Discussion}

This case report shows a typical case of temporal epilepsy that developed in adult age and was resistant to conventional treatment. The seizures appeared in remarkable coincidence with heavy exposure to organic solvents, disappearing shortly after discontinuance of exposure, and returning immediately after short term re-exposure.

Chronic epilepsy is not usually connected with solvent exposure, although a case-referent study on focal epilepsy has shown a just significant risk of the disease in heavily exposed subjects (printers). In that study the exposure classification was based on job category and no excess cases were seen in the less exposed groups. ${ }^{3}$

The EEG of the present case was abnormal during solvent exposure, but normal when exposure was terminated. This abnormality may have been an acute effect of exposure, ${ }^{1}$ but another possible cause was the antiepileptic treatment.

Increased low frequency activity on EEGs occurs in $10 \%-15 \%$ of the normal population, and more often among persons exposed to jet fuel, ${ }^{4}$ and among car painters exposed to mixtures of solvents. ${ }^{15}$ Low frequency activity can be interpreted as acute loss of neuronal func- 
tion, ${ }^{1}$ and is common among patients with solvent poisoning (40\%-72\%). ${ }^{1}$ The paroxysmal abnormalities characteristic of epileptic disorders have only been seen, however, in a small fraction $(5 \%)$ of persons exposed to solvents. ${ }^{1}$

By comparison with a never exposed reference group there was a doubling of the power of the EEG in patients with diagnosed solvent induced chronic toxic encephalopathy.

A significant reduction of EEG power was found at follow up after several years without exposure, although the level of the reference group was not reached. ${ }^{6}$

In conclusion, this case history suggests that exposure to organic solvent may elicit or maintain epileptic seizures despite medical treatment. This clinical picture may be explained by lowering of the threshold for seizures by the same mechanism as seen for alcohol.

1 Seppäläinen AM. Neurophysiological aspects of the toxicity of organic solvents. Scand 7 Work Environ Health 1985;11(suppl 1):61-4.

2 World Health Organisation and Nordic Council of Ministers Chronic effects of organic solvents on the central nervous system and diagnostic criteria. Copenhagen: WHO, 1985 .

3 Littorin ME. Fehling C. Attwell RG. Skerfving S Focal epilepsy and exposure to organic solvents. A casereferent study. F Occup Med 1988;30:805-8.

4 Knave B, Anshelm Olson B, Elofsson SA, et al. Long term exposure to jet fuel. A cross sectional epidemiologic investigation on occupationally exposed industrial work ers with special reference to the nervous system. Scand $\mathcal{F}$ Work Environ Health 1978;4:19-45.

5 Seppäläinen AM, Husman K, Mårteson C. Neurophysiological effects of long-term exposure to a mixture of organic solvents. Scand $\exists$ Work Environ Health 1978; 4:304-14.

6 Ørbaek P, Rosén I, Svensson K. Power spectrum analysis of EEG at diagnosis and follow up of patients with solvent induced chronic solvent encephalopathy. Br f Ind Med 1988;45:476-82. 